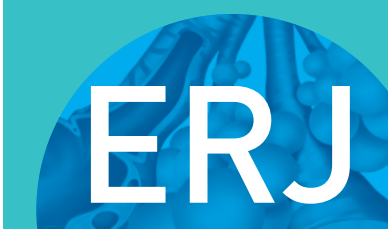

open research
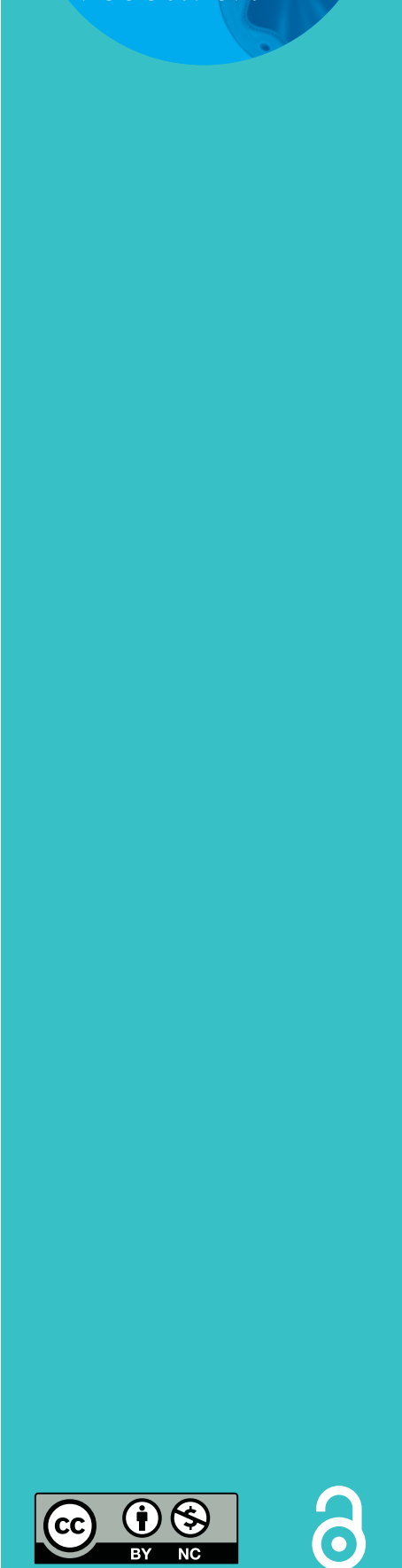

\section{Closed circuit rebreathing to achieve inert gas wash-in for multiple breath wash-out}

\author{
Alex R. Horsley ${ }^{1,2}$, Katherine O'Neill ${ }^{3}$, Damian G. Downey ${ }^{4}$, J. Stuart Elborn ${ }^{3,4}$, \\ Nicholas J. Bell ${ }^{5}$, Jaclyn Smith ${ }^{1}$ and John Owers-Bradley ${ }^{6}$
}

Affiliations: ${ }^{1}$ Institute of Inflammation and Repair, Education and Research Centre, University of Manchester, Manchester, UK. ${ }^{2}$ Manchester Adult Cystic Fibrosis Centre, University Hospital of South Manchester, Manchester, UK. ${ }^{3}$ Centre for Infection and Immunity, Queen's University Belfast, Belfast, UK. 'Belfast City Hospital, Belfast Health and Social Care Trust, Belfast, UK. ${ }^{5}$ Bristol Royal Infirmary, University Hospitals Bristol NHS Foundation Trust, Bristol, UK. ${ }^{6}$ School of Physics and Astronomy, University of Nottingham, Nottingham, UK.

Correspondence: Alex Horsley, Manchester Adult CF Centre, University Hospital of South Manchester, Manchester M23 9LT, UK. E-mail: alexander.horsleylamanchester.ac.uk

ABSTRACT Multiple breath wash-out (MBW) testing requires prior wash-in of inert tracer gas. Wash-in efficiency can be enhanced by a rebreathing tracer in a closed circuit. Previous attempts to deploy this did not account for the impact of $\mathrm{CO}_{2}$ accumulation on patients and were unsuccessful. We hypothesised that an effective rebreathe wash-in could be delivered and it would not alter wash-out parameters.

Computer modelling was used to assess the impact of the rebreathe method on wash-in efficiency. Clinical testing of open and closed circuit wash-in-wash-out was performed in healthy controls and adult patients with cystic fibrosis (CF) using a circuit with an effective $\mathrm{CO}_{2}$ scrubber and a refined wash-in protocol.

Wash-in efficiency was enhanced by rebreathing. There was no difference in mean lung clearance index between the two wash-in methods for controls $(6.5$ versus $6.4 ; \mathrm{p}=0.2, \mathrm{n}=12)$ or patients with $\mathrm{CF}$ (10.9 versus 10.8; $\mathrm{p}=0.2, \mathrm{n}=19)$. Test time was reduced by rebreathe wash-in ( 156 versus $230 \mathrm{~s}$ for $\mathrm{CF}$ patients, $\mathrm{p}<0.001)$ and both methods were well tolerated. End wash-in $\mathrm{CO}_{2}$ was maintained below $2 \%$ in most cases.

Rebreathe-wash-in is a promising development that, when correctly deployed, reduces wash-in time and facilitates portable MBW testing. For mild CF, wash-out outcomes are equivalent to an open circuit.

@ERSpublications

Refinements to wash-in methods permit a faster test and allow use of portable lung clearance index testing http://ow.ly/UYHiN

This article has supplementary material available from openres.ersjournals.com

Received: July 072015 | Accepted after revision: Nov 192015 | First published online: Month 02015

Support statement: This work was funded by a UK National Institute for Health Research (NIHR) Clinician Scientist award to A. Horsley. This report presents independent research funded by the NIHR. The views expressed are those of the authors and not necessarily those of the UK National Health Service, the NIHR or the UK Department of Health. Funding information for this article has been deposited with FundRef.

Conflict of interest: Disclosures can be found alongside this article at openres.ersjournals.com

Copyright CERS 2015. This article is open access and distributed under the terms of the Creative Commons Attribution Non-Commercial Licence 4.0 


\section{Introduction}

Multiple-breath inert gas wash-out (MBW) is a sensitive and valuable research tool in the assessment of patients with cystic fibrosis (CF) and mild airflow obstruction [1,2]. The MBW outcome measure lung clearance index (LCI) is more sensitive than conventional spirometry [3-5], correlates better with findings on computed tomography [6] and is sensitive to the beneficial effects of new therapies [7, 8]. A number of different systems are now marketed to measure LCI that comply to varying degrees with technology recommendations [9]. Success in research studies, however, has so far not been transferred into widespread adoption of routine MBW. MBW tests involve both a wash-in of inert tracer gas and a wash-out phase, regardless of whether nitrogen or exogenous tracer gas washout is used, and assessment can thus take in excess of $30 \mathrm{~min}$ [10]. Furthermore, both wash-out methodologies require fixed supplies of either $100 \%$ oxygen (to wash nitrogen out) or an $\mathrm{SF}_{6} /$ air mix (to wash this tracer gas in). This places restrictions on the portability of the apparatus and limits applications to secondary care.

Efficiency of wash-in can be improved by using a rebreathe technique in a closed circuit. This involves breathing in and out of a sealed bag filled with air supplemented with oxygen and an inert tracer gas (e.g. $\mathrm{SF}_{6}$ ). Rebreathe wash-in is more rapid than open circuit, since a higher concentration of tracer is taken into the lungs at the start of the test, and the final concentration is an equilibration of that between the bag and the lungs (figure 1). A further advantage is that large gas cylinders providing continuous high flows of tracer are not required. In the Innocor device (Innovision ApS, Odense, Denmark), a small on-board cylinder is used to prime the rebreathe bag, improving the portability of the system. The only prior report of this method used an early Innocor prototype that provided no method for removing $\mathrm{CO}_{2}$ from the circuit [11]. The build-up of $\mathrm{CO}_{2}$ within the rebreathe bag inevitably led to variable breathing patterns, and the researchers reported low success rates and high variability in functional residual capacity (FRC). Adding a scrubber to remove $\mathrm{CO}_{2}$ is a simple solution that has now allowed a more thorough and detailed examination of the rebreathe methodology.

We hypothesised that the closed circuit technique could be improved so that an effective wash-in could be achieved. We first investigated this using a computer lung model to explore the effect of ventilation heterogeneity on lung wash-in progression. We then investigated this clinically, comparing open to closed circuit wash-in in a group of healthy controls and patients with $\mathrm{SF}_{6}$. The specific aims of this study were: 1) to explore how ventilation heterogeneity and wash-in methodology affect efficiency of wash-in using a two-compartment computer lung model; 2) to compare the washout parameters LCI and FRC in healthy adult controls and patients with $\mathrm{CF}$, following open and closed circuit wash-in; 3) to compare the time taken to complete open and closed circuit wash-in; and 4) to compare patient experience of open and closed circuit wash-in.

\section{Materials and methods}

Wash-in modelling

A two-compartment computer lung model was prepared in Matlab (Mathworks Inc., Natick, MA, USA) to investigate the effect of wash-in protocol and ventilation heterogeneity on wash-in progression. Details are given in the supplementary material. In brief, it allowed control of lung, rebreathe bag and breath volumes, as well as the two major factors that influence washout progression: ventilation heterogeneity and deadspace (both common and lung compartment specific). This was compared to a conventional open circuit wash-in and to a modified rebreathe protocol designed to improve wash-in efficiency, which

FIGURE 1 Comparison of $\mathrm{SF}_{6}$ wash-in performed using an open and closed circuit from the same healthy control laligned to display wash-in start together). Rebreathe wash-in included six deep breaths at start of wash-in. This produced a spike of $\mathrm{SF}_{6}$ followed by more rapid equilibration of inspired and expired concentrations. Removal of $\mathrm{CO}_{2}$ results in a persistent small discrepancy between inspired and expired $\mathrm{SF}_{6}$, so wash-in was continued until this has been stable for $>30 \mathrm{~s}$.

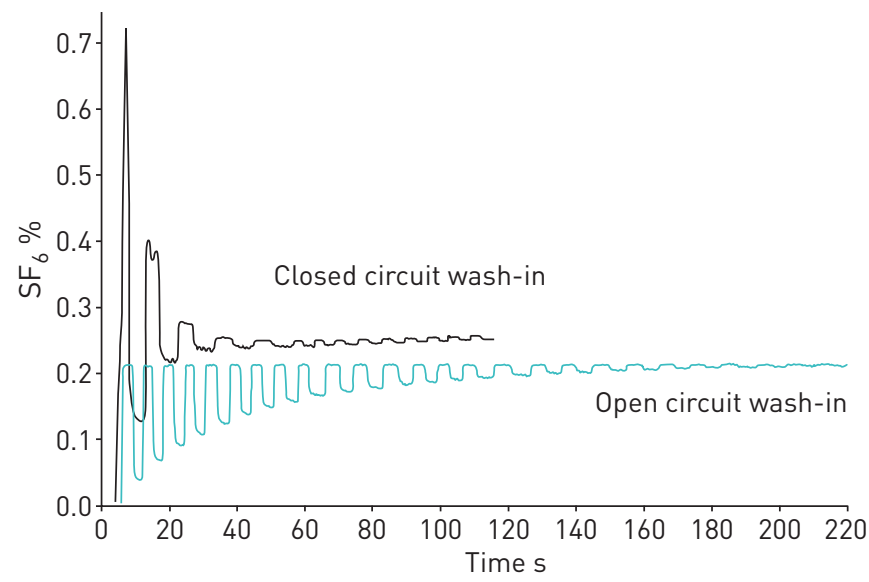


included six deep breaths at the start of wash-in. The following scenarios were then explored for all three wash-in protocols: 1) increasing specific ventilation heterogeneity to two equal volume lung compartments; and 2) increasingly unequal volume of the two lung compartments. As in clinical testing, apparent incompleteness was defined as the percentage difference between inspired and expired $\left[\mathrm{SF}_{6}\right]$. The model also allowed measurement of the true incompleteness of wash-in, here defined as the difference in $\left[\mathrm{SF}_{6}\right]$ between the two lung compartments, expressed as a percentage of the mixed expired $\left[\mathrm{SF}_{6}\right]$.

\section{Subjects}

Patients with CF were recruited from two UK adult CF centres. All patients had a confirmed diagnosis of $\mathrm{CF}$ and best forced expiratory volume in $1 \mathrm{~s}\left(\mathrm{FEV}_{1}\right)$ in the last 6 months of $\geqslant 50 \%$ predicted. For infection control purposes, patients also had to be free of infection with methicillin-resistant Staphylococcus aureus, Burkholderia cepacia complex and Mycobacterium abscessus. All participants were nonsmokers aged $>17$ years. Subjects provided signed informed consent. This study was reviewed by the Lancaster Research Ethics Committee (ref. 13/NW/0248).

Participants underwent sequential LCI assessments using the different wash-in protocols. Wash-in methodologies were grouped (i.e. triplicate open circuit followed by triplicate closed circuit, or vice versa). Technical constraints meant that the open circuit method was usually performed first, followed by a rest of $\geqslant 5$ min. Spirometry was performed after MBW assessments, according to European Respiratory Society/ American Thoracic Society standards [12]. Normative values for spirometry are those provided by the Global Lung Function Initiative [13].

\section{Wash-out apparatus}

Multiple breath wash-in and wash-out were performed using an Innocor MBW apparatus, which has been approved by the US Food and Drug Administraiton for this purpose. Open circuit wash-in was as previously described [3], using $0.2 \% \mathrm{SF}_{6}$ in air (BOC, Guildford, UK). The closed circuit consisted of a sealed 3- $\mathrm{L}$ bag filled with a mixture of room air and test gas $\left(94 \% \mathrm{O}_{2}, 1 \% \mathrm{SF}_{6}\right.$ and $\left.5 \% \mathrm{~N}_{2} \mathrm{O}\right)$. Switching between air and bag was controlled by fast-operating pneumatic valves triggered at the end of expiration, under the control of the operator (figure 2). Subjects performed wash-outs through the same patient

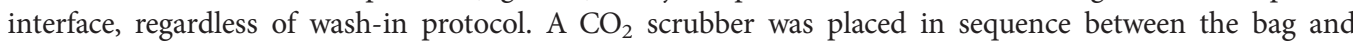
patient, so that expired air was depleted of $\mathrm{CO}_{2}$ prior to re-inspiration.

Based on the modelling data, a modified wash-in protocol was used in order to achieve a more efficient wash-in. This consisted of three novel components: 1) a double $\mathrm{CO}_{2}$ scrubber; 2) an increase in the fraction of the bag volume filled with test gas to $40 \%$, which increases inspired $\left[\mathrm{O}_{2}\right]$ at the start of wash-in and extends wash-in time before this falls below 20\%; and 3) six deep breaths at the start of wash-in, which increases total cumulative inspired volume as well as ensuring poorly ventilated compartments are reached at the start, when the inspired $\mathrm{SF}_{6}$ fraction is high. Wash-in was continued until the $\mathrm{SF}_{6}$ signal had been stable for $>30 \mathrm{~s}$. Removal of $\mathrm{CO}_{2}$ results in a persistent small discrepancy between inspired and expired $\mathrm{SF}_{6}$, so this was not always an entirely flat line, in which case the difference was required to be stable.

Six subjects underwent additional open circuit wash-in using a gas mix that included $2 \% \mathrm{CO}_{2}$. The details of these experiments are included in the supplementary material.

FIGURE 2 Diagram of rebreathe apparatus. The patient breathes through a filter and flow meter into a T-piece with two valve-controlled exits: one to room air and one to the rebreathe bag. This is filled with a mixture of air and test gas, and is enriched with $\mathrm{O}_{2}$ from the test gas. $\mathrm{A} \mathrm{CO}_{2}$ scrubber placed in series removes $\mathrm{CO}_{2}$ from expired air. The patient breathes either from the rebreathe bag with the air valve closed (wash-in) or breathes room air with the bag valve closed (wash-out).

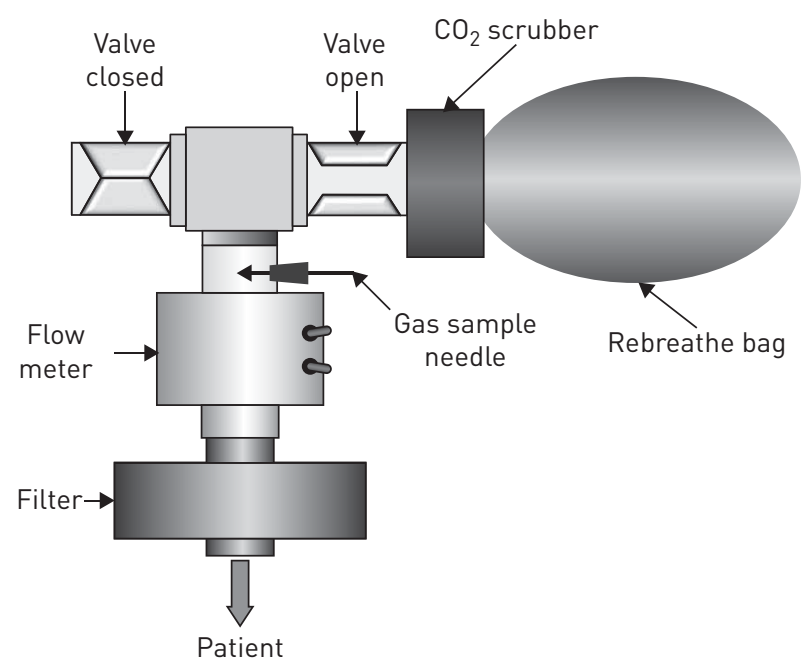




\section{Analysis}

Analysis of wash-in and wash-out was performed offline using software prepared in Igor Pro v6 (Wavemetrics Inc., Lake Oswego, OR, USA) as previously described [10]. "Incompleteness" of wash-in was defined as the difference between inspired and expired $\mathrm{SF}_{6}$ concentrations, expressed as a percentage of the inspired $\mathrm{SF}_{6}$. During rebreathe wash-in, adjustment was made for the effects of $\mathrm{CO}_{2}$ removal on the concentration of $\mathrm{SF}_{6}$. LCI and FRC were calculated according to recent guidelines, including adjustment for re-inspired $\mathrm{SF}_{6}$, and pre- and post-capillary deadspaces $(48$ and $12 \mathrm{~mL}$, respectively, for this adult MBW configuration) [9].

\section{Patient feedback}

At the end of wash-out testing, participants were asked to complete a questionnaire on their experience of the two methods. This contained free text responses and visual analogue scores (VASs) to rate the experience, using a questionnaire designed for this study and based on those used in previous studies [14]. VASs were expressed as a percentage of a maximum score of 100.

\section{Statistics}

Data were analysed using Prism (GraphPad Software Inc., San Diego, CA, USA). Normal distribution was assessed using the D'Agostino and Pearson omnibus normality test. Data are presented as mean $\pm \mathrm{SD}$ or median (interquartile range (IQR)) unless otherwise stated. Fisher's exact test was used to compare proportions. Bland-Altman analysis was used to compare LCI and FRC generated from different wash-in methods, and paired t-tests used to describe the significance of the difference between methods. Repeatability of tests was expressed as the coefficient of variation $(\mathrm{CoV})$ from wash-out repeats performed during a single sitting. A $p$-value $<0.05$ was considered to be statistically significant.

\section{Results}

\section{Wash-in modelling}

Full wash-in profiles across the different scenarios are presented in the supplementary material. A representative profile is shown in figure 3 for the different wash-in protocols in a case of moderately severe ventilation heterogeneity (first lung compartment volume 0.7 , fractional ventilation 0.3 , model LCI 10).

In both ventilation heterogeneity scenarios, a similar picture was observed: wash-in was prolonged by increasing ventilation or volume heterogeneity but was more efficient with the closed circuit method. Adding deep breaths at the start of wash-in deep led to a much more effective and rapid wash-in. Apparent incompleteness, however, fell much faster in a closed circuit, particularly if deep breaths were employed at the start of wash-in, than the true difference in $\mathrm{SF}_{6}$ between compartments.

\section{Clinical testing}

LCI from open circuit wash-in and modified rebreathe wash-in was compared in 31 subjects: 19 patients with CF patients and 12 healthy controls. Demographic and lung function data are presented in table 1.
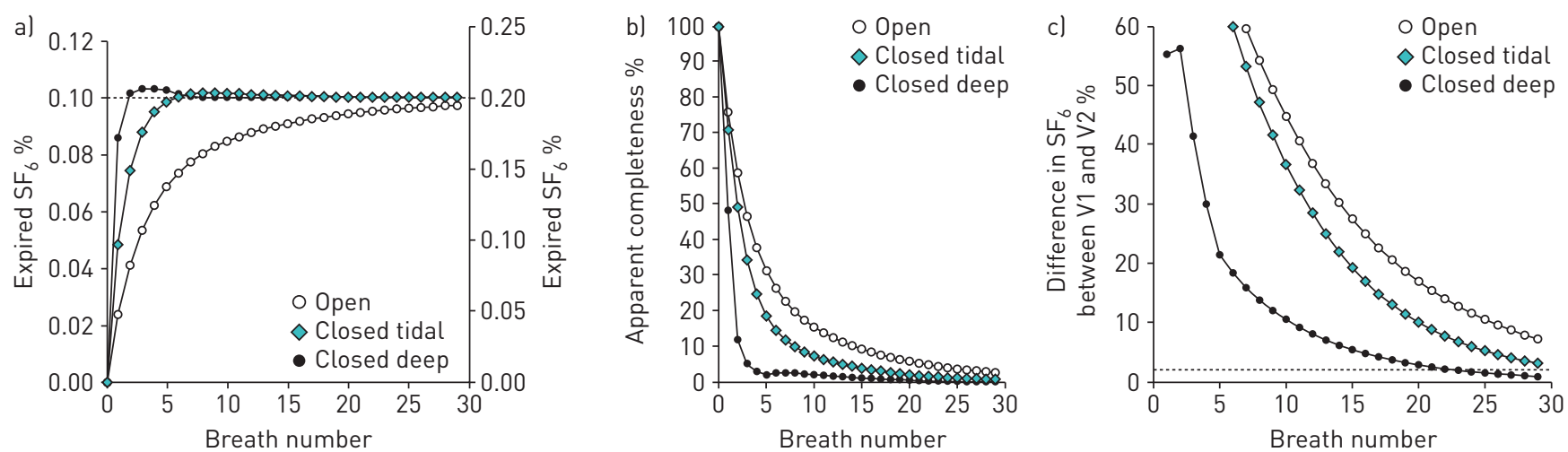

FIGURE 3 Effect of ventilation heterogeneity on wash-in progress. Wash-ins are all from a model with a first lung compartment volume (V1) of 0.7 and fractional ventilation 0.3 (giving a model lung clearance index of 10). Three different wash-in scenarios are presented: open circuit, closed circuit with tidal breaths and closed circuit with six deep breaths at the start of wash-in. al Wash-in progression, as shown by expired end-tidal $\mathrm{SF}_{6}$. Target end tidal $\mathrm{SF}_{6}$ (representing complete gas equilibrium throughout the model) is shown as a horizontal dotted line. Closed circuit washin to $0.1 \% \mathrm{SF}_{6}$ and open circuit wash-in to $0.2 \% \mathrm{SF}_{6}$ are shown to same scale on the different axes. b) Apparent wash-in incompleteness (measured as difference between inspired and expired $\mathrm{SF}_{6}$ concentrations at the mouth). c) True wash-in incompleteness, expressed as the percentage difference between $\mathrm{SF}_{6}$ concentrations in the two compartments. 
CF patients had lower spirometric parameters than controls and higher LCI. Neither FRC nor LCI were significantly different between open wash-in and rebreathe wash-in. Bland-Altman plots of these data are shown in figures 4 and 5, respectively. For LCI, there were similar 95\% limits of agreement (LOA) between the two methods to those previously been described for healthy subjects on different visits using open circuit wash-in (bias 0.1, LOA -0.4-0.6) [3]. For CF patients, the variability between the two wash-in methods was greater but was similar below an LCI of 13 (overall bias 0.2, LOA -1.0-1.3). A single subject had very much greater LCI from open versus closed circuit wash-in (15.6 versus 13.9) but he also had unstable wash-out measurements by both methods (CoV FRC 9\%, CoV LCI 7\%). Removing this outlier reduces the LOA by $18 \%$.

There was a reduction in wash-in time by $50 \%$ (controls) and $32 \%$ (CF patients) using the rebreathe method (table 2). Median (IQR) end wash-in $\mathrm{O}_{2}$ concentration was 23.1\% (19.0-26.4\%) for CF patients. End wash-in inspired $\mathrm{CO}_{2}$ was $<2 \%$ in all but one $\mathrm{CF}$ patient, and median end wash-in $\mathrm{CO}_{2}$ was not significantly different between CF and controls ( 1.3 versus $1.4 \%, \mathrm{p}=0.5)$. This does not appear to have had a significant effect on washout breathing patterns: mean $\pm \mathrm{SD}$ wash-out tidal volume $\left(V_{\mathrm{T}}\right)$ and respiratory rate were no different between open and closed wash-in $(847 \pm 168$ versus $883 \pm 186 \mathrm{~mL}(\mathrm{p}=0.09)$ and $14 \pm 4$ versus $13 \pm 4$ breaths per $\min (\mathrm{p}=0.06))$.

\section{Repeatability}

There were no statistically significant differences in repeatability for LCI or FRC, as measured by the CoV of repeat assessments performed at the same sitting. For CF patients, median (IQR) CoV for LCI was $2.1 \%$ $(0.9-3.6 \%)$ for open circuit wash-in versus 3.2\% (0.9-6.4\%) for closed circuit $(\mathrm{p}=0.5)$. For FRC, the CoV of repeat measurements was $3.5 \%(1.5-7.3 \%)$ for open circuit wash-in versus $4.8 \%$ (1.8-6.7\%) for closed circuit $(\mathrm{p}>0.9)$.

\section{Patient experience}

Questionnaires were collected from 24 participants, comprising 11 controls and $13 \mathrm{CF}$ patients (table 3). All wash-in protocols were generally well tolerated. There were no significant differences in VAS scores between open and closed methods or between CF patients and controls for any parameters. The most common comment about the tests in general (from 20 (83\%) respondents) were that they were "fine", "okay", "comfortable" or that the participant had "no problems". When asked to indicate the worst part of the test, the most common complaint was discomfort due to the nose clip in 10 (42\%) respondents.

TABLE 1 Summary demographic and washout data for control and cystic fibrosis subjects who completed repeat wash-out measurements with both an open circuit wash-in and a modified

closed circuit wash-in

\begin{tabular}{|c|c|c|c|}
\hline & $\begin{array}{l}\text { Healthy } \\
\text { volunteers }\end{array}$ & $\begin{array}{l}\text { Cystic } \\
\text { fibrosis }\end{array}$ & $\begin{array}{l}\text { p-value for healthy volunteers versus } \\
\text { cystic fibrosis }\end{array}$ \\
\hline Subjects n & 12 & 19 & \\
\hline Age years & $34.2 \pm 10.4$ & $30.2 \pm 6.2$ & 0.2 \\
\hline Males/females $n / n$ & $1 / 11$ & $13 / 6$ & 0.002 \\
\hline FEV $_{1}$ z-score & $-0.5 \pm 1.0$ & $-2.3 \pm 1.3$ & 0.0006 \\
\hline FVC z-score & $-0.1 \pm 1.2$ & $-1.2 \pm 1.2$ & 0.03 \\
\hline FEV $_{1} \%$ predicted & $-94.7 \pm 12.5$ & $71.9 \pm 15.9$ & 0.0005 \\
\hline $\mathrm{FEV}_{1} / \mathrm{FVC}$ & $0.80 \pm 0.07$ & $0.69 \pm 0.09$ & 0.003 \\
\hline $\mathrm{LCl}$ open & $6.5 \pm 0.5$ & $10.9 \pm 2.6$ & $<0.0001$ \\
\hline LCl closed & $6.4 \pm 0.5$ & $10.8 \pm 2.2$ & $<0.0001$ \\
\hline $\begin{array}{l}\text { p-value for open versus } \\
\text { closed }\end{array}$ & 0.2 & 0.2 & \\
\hline FRC open $L$ & $2.32 \pm 0.70$ & $2.66 \pm 0.81$ & 0.2 \\
\hline FRC closed L & $2.34 \pm 0.67$ & $2.75 \pm 0.80$ & 0.2 \\
\hline $\begin{array}{l}\text { p-value for open versus } \\
\text { closed }\end{array}$ & 0.6 & 0.1 & \\
\hline
\end{tabular}

Data are presented as mean \pm SD unless otherwise stated. $\mathrm{FEV}_{1}$ : forced expiratory volume in $1 \mathrm{~s}$; FVC: forced vital capacity; LCl: lung clearance index; FRC: functional residual capacity. 
FIGURE 4 Bland-Altman comparison of lung clearance index (LCI) from multiple breath wash-out following open and modified closed circuit wash-in for both healthy controls and patients with cystic fibrosis (CF). " : open minus closed.

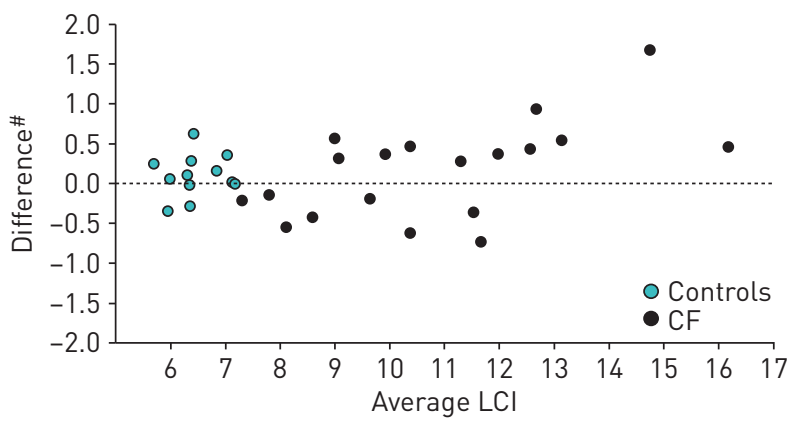

\section{Discussion}

This is the first study to systematically compare open and closed circuit wash-in methods using a closed circuit technique that includes an effective $\mathrm{CO}_{2}$ scrubber. We have shown that closed circuit wash-in is a simple and more rapid technique for equilibrating tracer gas into the lungs prior to a MBW. We have also shown that wash-in efficiency is enhanced by deep breaths at the start of wash-in and that this is necessary in order to achieve rapid wash-in in CF patients with ventilation heterogeneity. $\mathrm{CO}_{2}$ and $\mathrm{O}_{2}$ can be maintained in the rebreathe bag at levels that are safe and acceptable to patients. For patients with mild to moderate $\mathrm{CF}\left(\mathrm{FEV}_{1}>50 \%\right.$ predicted), this method did not result in systematic change in FRC, LCI or wash-out breathing patterns. When ventilation heterogeneity is severe, in other words, LCI is very high, the rebreathe wash-in described here may not achieve as effective wash-in as a much more prolonged open circuit wash-in. A possible effect of this is may be a lower LCI when LCI is above the mid-teens.

In order to aid interpretation of the clinical observations, we have developed a lung model to investigate wash-in progress in the context of ventilation heterogeneity. The model allows control of both deadspace and specific ventilation, and permits us to follow the tracer gas signal at the mouth and within the lung compartments. The results reveal that apparently complete wash-in can hide more significant differences between lung compartments. This is particularly the case with rebreathe wash-in, where although $<2 \%$ difference between inspired and expired $\mathrm{SF}_{6}$ concentration can be very rapidly achieved, this end-point is reached before adequate wash-in of less well ventilated lung compartments has occurred.

As a result of these observations, we have amended the wash-in method to incorporate deep inspirations at the start and to permit a more prolonged closed circuit wash-in. Wash-in can now be comfortably continued for 3 min without $\left[\mathrm{CO}_{2}\right]$ rising above $2 \%$ or $\left[\mathrm{O}_{2}\right]$ falling below that in room air. We have also shown that $\mathrm{CO}_{2}$ at this level does not appear to affect the LCI. This delivers two major advantages for the rebreathe method. Even though time savings overall may be modest (since wash-out time is unaffected), these are important in the context of clinical deployment, where test time is a major barrier to uptake. Unlike $\mathrm{N}_{2}$ wash-out, there is also no need to wait before starting the next wash-in, and the three tests follow after each other in rapid succession. In a recent attempt to introduce LCI measurements into a clinic setting, SINGER et al. [15] restricted themselves to a 20-min time window. In MBW-naïve children, they were unable to complete more than a single $\mathrm{N}_{2}$ wash-out assessment in $59 \%$ of subjects, which is insufficient for accurate reporting of LCI [9]. In response to this, attempts have been made to truncate the wash-out, ending at an earlier point $[10,16]$. The results have been disappointing, however, with modest time saved offset by a negative impact on sensitivity. With a correctly performed rebreathe wash-in, however, the time saving is at

FIGURE 5 Bland-Altman comparison of functional residual capacity (FRC) measured from multiple breath wash-out following open and modified closed circuit wash-in for both healthy controls and patients with cystic fibrosis (CF). ${ }^{\#}$ : open minus closed.

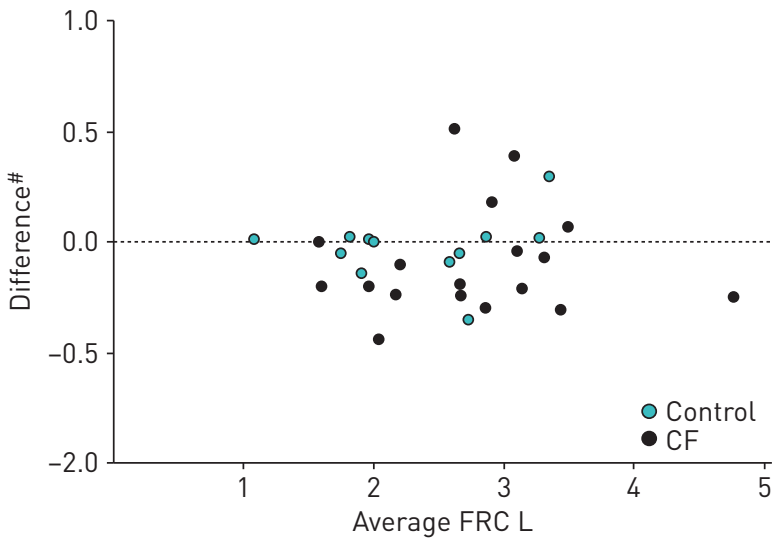


TABLE 2 Effect of wash-in methodology on wash-in time and other parameters

\begin{tabular}{lccc} 
& Open & Rebreathe & p-value for open versus rebreathe \\
\hline Healthy volunteers & & & \\
Total wash-in time s & $202(142-229)$ & $101(89-142)$ & 0.0005 \\
Cumulative inspired volume L & $19.8 \pm 4.3$ & $17.9 \pm 5.4$ & 0.2 \\
Wash-in incompleteness \% & $1.25 \pm 0.36$ & $0.53 \pm 0.60$ & 0.003 \\
$\quad$ Median end wash-in $\mathrm{CO}_{2} \%$ & & $1.4(1.0-3.5)$ & \\
Cystic fibrosis & & & $<0.0001$ \\
$\quad$ Total wash-in time s & $230(204-280)^{*}$ & $156(132-173)^{*}$ & 0.01 \\
Cumulative inspired volume L & $38.4 \pm 8.4^{\#}$ & $32.2 \pm 6.2^{\#}$ & 0.0007 \\
Wash-in incompleteness \% & $1.76(0.74)$ & $1.18(0.82)^{*}$ & \\
Median end wash-in $\mathrm{CO}_{2} \%$ & & $1.3(1.1-1.7)$ & \\
\hline
\end{tabular}

Data are presented as median (interquartile range) or mean \pm SD, unless otherwise stated. *: $p<0.05$ for healthy volunteers versus $\mathrm{CF} ;{ }^{\#}: \mathrm{p}<0.0001$ for healthy volunteers versus $\mathrm{CF}$.

least as great and the signal component of the LCI is preserved. Since the objective of this study was to compare closed circuit to conventional MBW, we have not assessed the impact of deep breathing on open circuit wash-in. It is likely that this would also serve to reduce wash-in time. However, the other major advantage of rebreathe wash-in is that the MBW apparatus is rendered genuinely portable and has since been mounted on a medical cart with an on-board power supply for bedside MBW measurements.

It is important to consider why the experience of closed circuit MBW here was so substantially different to that reported by PITTMAN et al. [11]. Their study used an early prototype Innocor-rebreathe, without a $\mathrm{CO}_{2}$ scrubber and with automated wash-in algorithms that had not been tested in clinical practice. It is clear that their subjects found rebreathing uncomfortable, resulting in a tendency to take deeper breaths that was restricted by the low filling volume of the bag $\left(1.5 V_{\mathrm{T}}\right)$. This early failure of the closed circuit method led to a recommendation against the technique [1]. In many regards, the experience of PITTMAN et al. [11] mirrors our own early observations when such protocols were attempted. In order to overcome this, we have deployed an effective $\mathrm{CO}_{2}$ scrubber that limits accumulation of $\mathrm{CO}_{2}$ to typically $<2 \%$. We use inspiratory volume feedback to help patients maintain a regular $V_{\mathrm{T}}$ throughout the latter part of wash-in and wash-out. However, we also fill the bag to a volume of at least $\geqslant 3 V_{\mathrm{T}}$ (range 2-3 L), which accommodates deeper breaths and ensures that inspired $\mathrm{O}_{2}$ remains $>20 \%$. Instead of an automated end of wash-in algorithm, we use manual control of wash-in termination, based upon recognition of stable expired $\mathrm{SF}_{6}$ signals for $\geqslant 30 \mathrm{~s}$. Finally, the measurement of FRC reported here was obtained from wash-out, as per open circuit methods, and in contrast to the earlier report. In this study, patient experience of both open and closed circuit methods was good, with no significant differences in comfort scores between the two methods.

An inherent disadvantage of the rebreathe method is that it is may not be suitable for those with very abnormal gas mixing and thus very high LCI. An effective wash-in may not always be achieved throughout the lungs in this scenario within the wash-in time described here, though further developments to permit

\begin{tabular}{|c|c|c|c|c|}
\hline & \multicolumn{2}{|c|}{ Healthy volunteers } & \multicolumn{2}{|c|}{ Cystic fibrosis } \\
\hline & Open & Closed & Open & Closed \\
\hline Subjects n & \multicolumn{2}{|c|}{11} & \multicolumn{2}{|c|}{13} \\
\hline Males/females $\mathrm{n} / \mathrm{n}$ & \multicolumn{2}{|c|}{$1 / 10$} & \multicolumn{2}{|c|}{$10 / 3$} \\
\hline Age years & \multicolumn{2}{|c|}{$34.4 \pm 10.8$} & \multicolumn{2}{|c|}{$31.0 \pm 5.3$} \\
\hline $\mathrm{LCl}$ & \multicolumn{2}{|c|}{$6.6(0.5)$} & \multicolumn{2}{|c|}{$10.9(2.2)$} \\
\hline \multicolumn{5}{|l|}{ VAS score } \\
\hline Ease of wash-out \% & $93(71-96)$ & $85(80-91)$ & 93 (81-99) & 87 (78-96) \\
\hline Ease of wash-in \% & $96(95-100)$ & $95(79-100)$ & 89 (80-97) & $87(72-93)$ \\
\hline Time taken to complete $\%$ & $81(78-97)$ & $87(79-97)$ & 77 (69-95) & 81 (69-95) \\
\hline
\end{tabular}


longer wash-in may support this. In reality, however, these are not the patients in whom MBW testing should be targeted [17]. The advantages and strengths of LCI in particular appear to be in those with mild airways disease and rebreathe wash-in is equivalent to open circuit in these patients. In conclusion, we have demonstrated the successful adaptation and deployment of a novel rebreathe methodology to perform inert gas wash-in. We have also developed a lung model that considerably aids the design of improved protocols for wash-out measurements. We have shown that rebreathe wash-in permits the use of a portable system that reduces wastage of tracer gas and avoids potential confounding effects of body $\mathrm{N}_{2}$ on washout parameters. Although this method cannot easily be implemented to aid the use of $\mathrm{N}_{2} \mathrm{MBW}$, it can be applied to any system based on inhaled tracer gases. This is an important new development in MBW testing that will facilitate rapid and portable measurement of LCI.

\section{Acknowledgements}

The authors are most grateful to all the volunteers who participated in these studies. We would also like to thank the Respiratory and Allergy Clinical Research Facility, North West Lung Centre, Manchester (UK), where much of the clinical and development work was conducted. The authors would also like to acknowledge the assistance provided by the University of Manchester Dept of Medical Physics, Salford Royal Infirmary (Salford, UK), and the Northern Ireland Clinical Research Network (Respiratory Health) for infrastructure support.

\section{References}

1 Kent L, Reix P, Innes JA, et al. Lung clearance index: evidence for use in clinical trials in cystic fibrosis. J Cyst Fibros 2014; 13: 123-138.

2 Horsley A, Siddiqui S. Putting lung function and physiology into perspective: cystic fibrosis in adults. Respirology 2015; 20: 33-45.

3 Horsley AR, Gustafsson PM, Macleod KA, et al. Lung clearance index is a sensitive, repeatable and practical measure of airways disease in adults with cystic fibrosis. Thorax 2008; 63: 135-140.

4 Aurora P, Gustafsson P, Bush A, et al. Multiple breath inert gas washout as a measure of ventilation distribution in children with cystic fibrosis. Thorax 2004; 59: 1068-1073.

5 Gustafsson PM, Aurora P, Lindblad A. Evaluation of ventilation maldistribution as an early indicator of lung disease in children with cystic fibrosis. Eur Respir J 2003; 22: 972-979.

6 Gustafsson PM, De Jong PA, Tiddens HA, et al. Multiple-breath inert gas washout and spirometry versus structural lung disease in cystic fibrosis. Thorax 2008; 63: 129-134.

7 Davies J, Sheridan H, Bell N, et al. Assessment of clinical response to ivacaftor with lung clearance index in cystic fibrosis patients with a G551D-CFTR mutation and preserved spirometry: a randomised controlled trial. Lancet Respir Med 2013; 1: 630-638.

8 Amin R, Subbarao P, Lou W, et al. The effect of dornase alfa on ventilation inhomogeneity in patients with cystic fibrosis. Eur Respir J 2011; 37: 806-812.

9 Robinson PD, Latzin P, Verbanck S, et al. Consensus statement for inert gas washout measurement using multiple- and single- breath tests. Eur Respir J 2013; 41: 507-522.

10 Hannon D, Bradley JM, Bradbury I, et al. Shortened Lung Clearance Index is a repeatable and sensitive test in children and adults with cystic fibrosis. BMJ Open Respir Res 2014; 1: e000031.

11 Pittman JE, Johnson RC, Jones PW, et al. Variability of a closed, rebreathing setup for multiple breath wash-out testing in children. Pediatr Pulmonol 2012; 47: 1242-1250.

12 Miller MR, Hankinson J, Brusasco V, et al. Standardisation of spirometry. Eur Respir J 2005; 26: 319-338.

13 Quanjer PH, Stanojevic S, Cole TJ, et al. Multi-ethnic reference values for spirometry for the 3-95-yr age range: the global lung function 2012 equations. Eur Respir J 2012; 40: 1324-1343.

14 Rowan SA, Bradley JM, Bradbury I, et al. Lung clearance index is a repeatable and sensitive indicator of radiological changes in bronchiectasis. Am J Respir Crit Care Med 2014; 189: 586-592.

15 Singer F, Kieninger E, Abbas C, et al. Practicability of nitrogen multiple-breath washout measurements in a pediatric cystic fibrosis outpatient setting. Pediatr Pulmonol 2013; 48: 739-746.

16 Yammine S, Singer F, Abbas C, et al. Multiple-breath washout measurements can be significantly shortened in children. Thorax 2013; 68: 586-587.

17 Horsley A. Lung clearance index in the assessment of airways disease. Respir Med 2009; 103: 793-799. 